http://www.doctors.net.uk/onlinebooks/ main.aspx?book=62 (accessed 13 Mar 2008)

3. Silver N. Headache (Chronic tension-type). In: BM Clinical Evidence. http://clinicalevidence.bmj.com/ ceweb/conditions/nud/1205/1205.jsp (accessed 13 Mar 2008).

DOI: 10.3399/bjgp08X279904

\section{Headache management in general practice}

Reading David PB Watson ${ }^{1}$ and David Kernick, ${ }^{2}$ we are really impressed by the strong similarities between the UK and Italian situation in this field.

As a neurologist working in a headache centre (out-patients service) in Milan, and a GP with teaching roles, we agree of course with all the theoretical statements by Watson $(90 \%$ primary headache, no need for imaging in most cases, etcetera), and also with the complaint about limited GPs' interest and participation in headache patients' care and follow-up.

We have just one remark to add: for a correct diagnosis, a careful history is very important, but what is also useful is a neurological examination (and maybe a fundus of the eye examination). Both could be performed by a skilled GP, and only in some cases may require a specialist consultation.

Also for follow-up, GPs, being closer to their patients than specialists, could obtain easier careful registration for the course of headache attacks, and could prevent medication abuse.

\section{Marina Mesina}

Department of Neurology - Headache

Centre, St. Charles Hospital, Milan.

E-mail: marina.mesina@sancarlo.mi.it

\section{Francesco Carelli}

Professor GP, University of Milan.

\section{REFERENCES}

1. Watson D. Easing the pain: challenges and opportunities in headache management. $\mathrm{Br} \mathrm{J} \mathrm{Gen}$ Pract 2008; 58(547): 77-78.

2. Kernick D, Stapley S, Hamilton W. GPs' classification of headache. Br J Gen Pract 2008; 58(547): 102-104.

\section{Sexual problems in later life}

James Warner and colleagues are right to argue that older people are less reticent in discussing their sexual activity and problems than doctors believe. ${ }^{1}$ In a randomised controlled trial of health promotion with patients aged 65 years and over recruited through general practice, we asked 1090 responders the question: 'How often have you experienced sexual problems in the last month?' The choice of answers was 'never', 'seldom or sometimes' and 'often or always'. One thousand and-fifty-three (93.6\%) answered the question, of whom 72 (6.8\%) answered 'seldom or sometimes' and another 72 (6.8\%) answered 'often or always'. Among men, 121 (25\%) reported that they had a sexual problem, while only 23 (4\%) women did so. Sexual problems were reported by $17 \%$ of those aged 65 to 74 years, $21.5 \%$ of those aged 75 to 84 years, but only $4 \%$ of those aged 85 years and over. We do not know what the sexual problems were, and can only speculate that the predominance of men suggests that prostatic hypertrophy, medication adverse effects, or diabetic neuropathies were major causes. Further investigation is needed here. We do know that there was no association between having sexual problems and self-rated health; $33.5 \%$ of those rating their health as good to excellent also reported sexual problems, compared with $30 \%$ of those describing their health as fair or poor. Our sample was self-selected and relatively well (those with significant disabilities were excluded from the trial), so we may be under-estimating the prevalence of sexual problems in later life. The clinical implications for GPs are that sensitive discussion of sexual problems with men, up to the age of 85 years, is likely to reveal a significant burden of morbidity, but it is not clear whether it will be tractable. If our findings are typical, few older women will report sexual problems.

\section{Steve lliffe}

Professor, Research Department of Primary

Care, UCL, Royal Free Campus, Rowland Hill

Street, London NW3 2PF.

E-mail: s.iliffe@pcps.ucl.ac.uk

\section{Kalpa Kharicha}

Senior Research Fellow,

University College London

\section{Daniel Harari}

Consultant Geriatrician,

Kings College London

\section{Cameron Swift}

Professor of Medicine for the Elderly, Kings College London

\section{Andreas Stuck \\ Professor of Geriatric Medicine, University of Bern, Switzerland.}

\section{REFERENCES}

1. Warner J, Starren E, Walker G. Sexual enquiry in older people. Br J Gen Pract 2008; 58(547): 125-126.

2. Stuck AE, Kharicha K, Dapp U, et al. The ProAge study: an international randomised controlled study of Health Risk Appraisal for older persons based in general practice. BMC Med Res Methodol 2007; 7: 2.

DOI: 10.3399/bjgp08X279940

\section{Antibiotic-associated diarrhoea}

Our vocational training group discussed the paper of Conway, et al with great interest. ${ }^{1}$

Antibiotics change the microbial balance in the gastro-intestinal tract and can cause antibiotic associated diarrhoea (AAD). Antibiotics are frequently prescribed in general practice and AAD is common among this population. The rates of $A A D$ vary from $3 \%$ (penicilline $G$ and $V$ ) to $23 \%$ (amoxicillin clavulanate) depending upon the specific type of antibiotic. A study in children showed that this variation is statistically significant. ${ }^{2}$ AAD might be caused by the disruption of the normal flora and overgrowth of pathogens. ${ }^{3}$ Probiotics have been suggested to prevent AAD by restoration of the gut microflora.

In the study of Conway et al, all patients who were prescribed a 1-week course of 
antibiotics are included. Nevertheless, the authors do not take into account the fact that different antibiotic agents cause diarrhoea at a different rate. They also do not report a subgroup analysis on antibiotic agents.

Thus, the authors'conclusion that yogurt has no effect might be biased by the possibility that small-spectrum antibiotics represented a substantial part of all antibiotics applied in the study. The results might probably have been different when small spectrum antibiotics would have been excluded from the study or when a statistical correction would have been applied.

We would ask the authors if they could present data on the antibiotics prescribed in the study, and if they could specify the outcomes for patients using small versus broad-spectrum antibiotics.

\section{Karlijn Overeem}

MD, GP-trainee at Huisartsopleiding VU

Medical Centre Amsterdam.

E-mail:k.overeem@vumc.nl,

\section{Geertje van Soest}

$M D, G P$-trainee at Huisartsopleiding VU Medical Centre Amsterdam.

\section{Nettie Blankenstein}

$M D, P h D, E M G O$ institute and

Huisartsopleiding VU Medical Centre

Amsterdam.

\section{REFERENCES}

1. Conway S, Hart A, Clark A, Harvey I. Does eating yogurt prevent antibiotic-associated diarrhoea? A placebo controlled randomised controlled trial in general practice. Br J Gen Pract 2007; 57(545): 953-959.
2. Turck D, Bernet JP, Marx J, et al. Incidence and risk factors of oral antibiotic-associated diarrhoea in an outpatient pediatric population. J Pediatr Gastroenterol Nutr 2003; 37(1): 22-26.

3. Bergogne-Berezin E. Treatment and prevention of antibiotic associated diarrhoea. Int J Antimicrob Agents 2000; 16(4): 521-526.

DOI: 10.3399/bjgp08X279959

\section{Earwax}

We thank Weller for his response to our paper ${ }^{1}$ and support his view that the focus of management should be the alleviation of symptoms. We also agree that patient satisfaction with bulb treatment might be greater than shown by our data if bulbs were readily available, so avoiding the need to visit a GP practice.

Regarding the choice of wax-softening drops: although we cited the slightly more recent systematic review by $\mathrm{Hand}^{2}$ we do not feel that its conclusions differ significantly from the Cochrane review. ${ }^{3}$ Our statement that 'it is not known which wax-softening drops are most effective' is justified by both reviews. With the proviso that, as both reviews agree, there is a dearth of reliable data, we agree with Weller that water may indeed be as effective as sodium bicarbonate. However, as the objective of our study was to assess the effectiveness of bulb syringes, the choice of drops was secondary. Our choice was informed by the current literature to favour a water-based product over the more commonly used olive oil. We did consider water but felt that its use, in this context, was not common practice. Further, as the evidence base is weak, we were concerned that advocating it to colleagues might prove an impediment to recruitment. We therefore made a pragmatic choice of sodium bicarbonate which also had the advantage of being available in standard dropper bottles.

\section{Richard Coppin}

GP, The Surgery, Station Road, Overton, Hants, RG25 3DU.

E-mail: richard.coppin@nhs.net

\section{Dorothy Wicke}

Research Nurse, The Surgery, Station Road, Overton, Hants

\section{Paul Little}

Professor of Primary Care Research, University of Southampton Primary Medical Care, Aldermoor Health Centre, Southampton.

\section{REFERENCES}

1. Coppin R, Wicke D, Little P. Managing earwax in primary care: efficacy of self-treatment using a bulb syringe. Br J Gen Pract 2008; 58(546): 44-49.

2. Hand C, Harvey I. The effectiveness of topical preparations for the treatment of earwax: a systematic review. Br J Gen Pract 2004; 54(508): 862-867.

3. Burton MJ, Doree CJ. Ear drops for the removal of ear wax. Cochrane Database of Systematic Reviews 2003, Issue 3. Art. No.: CD004326.

DOI: 10.3399/bjgp08X279995

\section{Corrections}

In the March 2008 issue of the BJGP, we incorrectly published the title and an author's name in the following article:

Dormandy E, Gulliford MC, Reid EP, et al. Delay between pregnancy confirmation and sickle cell and thalassaemia screening: a population-based cohort study. Br J Gen Pract 2008; 58(548): 154-159.

1. The title above is shown correctly, with 'and' appearing before 'thalassaemia'. This omission was made in the article and on the contents page.

2. In the blue box on page 154, the author's name 'M Marteau', should have read 'TM Marteau'. We apologise for these errors. The corrected versions are available online. 